Int. J. Electrochem. Sci., 15(2020) $5682-5697$

\title{
Steady-State Substrate and Product Concentrations for Non- Michaelis-Menten Kinetics in an Amperometric Biosensor - Hyperbolic Function and PadéApproximants Method
}

\author{
Karuppusamy Nirmala ${ }^{1}$, Balu Manimegalai ${ }^{2}$, Lakshmanan Rajendran $^{2, *}$ \\ ${ }^{1}$ Department of Mathematics, Kalasalingam Academy of Research and Education, Srivilliputhur- \\ 626126, Tamilnadu \\ ${ }^{2}$ Department of Mathematics, AMET Deemed to be University, Kanathur, Chennai-603112. \\ "E-mail: $\underline{\text { raj_sms@ rediffmail.com }}$
}

doi: $10.20964 / 2020.06 .09$

Received: 27 January 2020/ Accepted: 30 March 2020 / Published: 10 May 2020

\begin{abstract}
A theoretical model is presented for an amperometric biosensor with inhibition of the substrate. This model is based on the non-stationary diffusion equations which contains a non-linear term connected to the enzymatic reaction of non-Michaelis-Menten kinetics. This paper describes the analytical representation of concentrations for steady-state conditions and for all parameter values. Hyperbolic function and Padé approximants method are used to evaluate the analytical expressions of concentration of substrate, product, substrate flux and current. A comparison of our estimated analytical results with the numerical simulation and previous analytical results available is provided. This observed a good agreement.
\end{abstract}

Keywords: Mathematical modeling; Non-linear equation; Hyperbolic function method; Padé approximants method; Amperometric biosensor; Non-Michaelis-Menten kinetics; Substrate Inhibition; Steady-state.

\section{$\underline{\text { FULL TEXT }}$}

(C) 2020 The Authors. Published by ESG (www.electrochemsci.org). This article is an open access article distributed under the terms and conditions of the Creative Commons Attribution license (http://creativecommons.org/licenses/by/4.0/). 